\title{
HOLOCAUSTO ECOLÓGICO EM ITAIPU E NA AMAZÔNIA: TRABALHADORES(AS), DITADURA E CONFLITO AGRÁRIO DO SUL AO NORTE DO BRASIL
}

\author{
Cátia Franciele Sanfelice de Paula ${ }^{1}$
}

\begin{abstract}
Resumo: O artigo problematiza a relação entre a Itaipu Binacional, a ditadura militar e a questão agrária na Amazônia, com ênfase nos problemas enfrentados pelos trabalhadores (as) desapropriados (as) pela estatal. Para isso, utilizo fontes de imprensa e registros produzidos pelo Serviço Nacional de Inteligência da ditadura militar, SNI, que tratam, em especial, dos conflitos no Acre e em Rondônia. Discuto a omissão e a truculência do Estado com relação aos conflitos agrários, do Sul ao Norte do país e como imobiliárias particulares atuaram nesse processo convocando trabalhadores do Paraná para a Amazônia. Destaco a falta de alternativas e as dificuldades de acesso à terra pelos trabalhadores frente às mudanças provocadas pelas relações sociais capitalistas materializadas na construção da Hidrelétrica de Itaipu e nos projetos de "colonização" na região Norte do país.
\end{abstract}

Palavras-chave: Amazônia. Trabalhadores. Itaipu Binacional. Conflito Agrário. Ditadura.

\section{ECOLOGICAL HOLOCAUST IN ITAIPU AND IN THE AMAZON: WORKERS, DICTATORSHIP AND AGRARIAN CONFLICT FROM THE SOUTH TO THE NORTH OF BRAZIL}

\begin{abstract}
The article discusses the relationship between Itaipu Binacional, the military dictatorship, and the agrarian issue in the Amazon, with emphasis on the problems faced by workers who are disappropriated by the State. For this, I use press sources and records produced by the National Intelligence Service of the military dictatorship, SNI, which deal, in particular, with conflicts in Acre and Rondônia. I discuss the omission and truculence of the State concerning agrarian conflicts, from the South to the North of the country, and how private real estate agents acted in this process by summoning workers from Paraná to the Amazon. I highlight the lack of alternatives and the difficulties of access to land by workers in the face of the changes caused by the capitalist social relations that materialized in the construction of the Itaipu Hydroelectric Power Plant and the projects of "colonization" in the northern region of the country.

Keywords: Amazon. Workers. Itaipu Binacional. Agrarian Conflict. Dictatorship.

\section{HOLOCAUSTO ECOLÓGICO EN ITAIPU Y EN LA AMAZONÍA: OBREROS(AS), DICTADURA Y CONFLICTO AGRARIO DEL SUR AL NORTE DE BRASIL}

Resumen: El artículo analiza la relación entre la Itaipú Binacional, la dictadura militar y el tema agrario en la Amazonía, con énfasis en los problemas que enfrentan los trabajadores que son desapropiados por la estatal. Para ello, utilizo fuentes de prensa y registros producidos por el Servicio Nacional de Inteligencia (SNI) de la dictadura militar, que tratan, en particular, de conflictos en Acre y Rondônia. Discuto la omisión y la truculencia del Estado en relación con los conflictos agrarios, desde el sur hasta el norte del país, y como agentes inmobiliarios privados actuaron en este proceso convocando trabajadores de Paraná para la Amazonía. Me gustaría señalar, en esta investigación, la falta de alternativas y las dificultades de acceso a la tierra por

\footnotetext{
${ }^{1}$ Doutora em História Social pela Universidade Federal de Uberlândia (UFU) (2018). Desde 2013 é professora de Teoria e Filosofia da História na Universidade Federal de Rondônia (Unir). Coordena o Núcleo de Pesquisa e Estudos em História, Trabalho e Educação em Rondônia (NUPEHT-RO). Vice coordenadora do Núcleo em História Pública da Amazônia (NUHPAM).
} 
parte de los trabajadores ante los cambios causados por las relaciones sociales capitalistas materializadas en la construcción de la Hidroeléctrica de Itaipú y en los proyectos de "colonización" en la región Norte del país.

Palabras clave: Amazonía; Trabajadores; Itaipu Binacional; Conflicto Agrario; Dictadura.

\section{Introdução}

Inicio com uma questão fundamental: Qual a relação entre a Itaipu Binacional, a ditadura militar e a Amazônia² ${ }^{2}$ A Hidrelétrica de Itaipu foi construída no Rio Paraná, localizado na região Oeste do Paraná, em 1982, durante a ditadura civil militar. Os impactos ambientais e humanos provocados pela construção da estatal foram de grande monta e há uma historiografia ${ }^{3}$ vasta que trata sobre o tema. Mazarollo (2003), ao destacar os danos causados pela Hidrelétrica, os denominou de holocausto ecológico, título do último capítulo de sua obra, já que a devastação da fauna e da flora e o custo social foi incalculável. A partir desse processo, surgiram diversas organizações em busca de indenização e reassentamento no Paraná.

Em 13/04/1980, o jornal Ilha Grande, editado na cidade de Guaíra/PR, anunciou que a Itaipu Binacional realizaria intermediação de terras junto as famílias afetadas com a construção da Hidrelétrica de Itaipu para a região Norte do país. Nesse período, os trabalhadores rurais desapropriados e pescadores 4 já haviam se organizado em movimento na luta pelo pagamento das indenizações. Já algumas famílias, que residiam nas regiões alagadas, receberam um baixo valor indenizatório, o que as impossibilitavam de adquirir novas terras no Paraná. A alternativa seria migrar para outras regiões do Norte do país. Esta ação nem de longe pode ser considerada uma questão de respeito pela Itaipu ou de preferência dessas famílias, como anunciara o jornal, e sim, uma necessidade.

\footnotetext{
${ }^{2}$ Neste artigo a referência à Amazônia diz respeito ao Estado do Acre e a Rondônia, estados evidenciados nas fontes que foram levantadas.

${ }^{3}$ Dentre os trabalhos que tratam sobre os impactos causados pela construção da Hidrelétrica de Itaipu destaco: PAULA. Cátia Franciele Sanfelice de. Mudanças no mundo dos trabalhadores: os pescadores profissionais de Guaíra/ PR (1970-2011) / Cátia Franciele Sanfelice. - Marechal Cândido Rondon, 2012; SCHMITT, Judite Veranisa. Os atingidos por Itaipu: história e memória. Oeste do Paraná, décadas de 1970 a 2000 / Judite Veranisa Schmitt. - Marechal Cândido Rondon, 2008; MASCARENHAS, Milena Costa. Poeira x Unicon: confrontos e contrapontos entre expropriados e Itaipu - Marechal Cândido Rondon, 2011; MAZZAROLLO, Juvêncio. A taipa da injustiça: esbanjamento econômico, drama social e holocausto ecológico em Itaipu. 2. ed. São Paulo: Loyola, 2003; MAZZAROLLO, Juvêncio. A taipa da injustiça: Itaipu x Agricultores expropriados. Comissão Pastoral da Terra. Secretariado Regional do Paraná, Curitiba, 1980; MANARIN, Ordilei. Peões da barragem. Memórias e relações de trabalho dos operários da construção da Hidrelétrica de Itaipu - 1975-1991. Marechal Cândido Rondon, 2008.

${ }^{4}$ Sobre os pescadores profissionais de Guaíra ver: PAULA. Cátia Franciele Sanfelice de. Mudanças no mundo dos trabalhadores: os pescadores profissionais de Guaíra/ PR (1970-2011) / Cátia Franciele Sanfelice. - Marechal Cândido Rondon, 2012.
} 
Desde a década de 1970, diversos projetos de "colonização" estavam sendo desenvolvidos na região Norte do país. Qual a relação da estatal com tais projetos? Para tratar dessa questão, neste artigo busco evidenciar, em especial, as relações que se deram no Acre e em Rondônia, e o papel da Itaipu e do Estado frente aos trabalhadores desapropriados no Paraná. A escolha por esta abordagem se deve ao conjunto de registros produzidos pelo SNI (Serviço Nacional de Inteligência da Ditadura Militar) dos quais tive acesso.

Destaco, que os trabalhos pioneiros sobre os registros produzidos pelo Serviço Nacional de Inteligência - SNI, foram elaborados pelo historiador Carlos Fico ${ }^{5}$. Na avaliação do autor, em 2008, do total de documentos que haviam sido liberados, nem 5\% haviam sido objeto de pesquisa histórica profissional (FICO, 2008). No que se refere a Amazônia, a produção se faz incipiente frente ao número de registros produzidos.

\section{A incerteza vivida pelos trabalhadores desapropriados no Paraná: Para onde ir?}

Registros como o do jornal O Parceleiro ${ }^{6}$, editado em Ariquemes/RO, evidenciam e apontam a natureza da intermediação. A reportagem "Conflitos. Incra ${ }^{7}$-Itaipu assentam novos colonos (A maioria deles não conhece a área onde serão assentados) " de 04 de julho de 1981, traz um histórico dos problemas que os trabalhadores passavam no Paraná, porém, enalteceu e construiu uma narrativa sobre a saída dos trabalhadores de suas terras em benefício da estatal, corroborando assim, para a construção de uma imagem de "progresso" e "desenvolvimento" em torno dos benefícios que a Itaipu geraria. A historiadora Milene Mascarenhas menciona que "somente no lado da fronteira brasileira, a desapropriação atingiu cerca de 40 mil habitantes, entre eles, proprietários de terra, posseiros, arrendatários, indígenas, comerciantes, entre tantos outros" (2011, p. 13).

O número apresentado pelo jornal era de 3 mil atingidos, e estava muito aquém do número real de trabalhadores desapropriados. O ano de 1981, período em que a reportagem foi publicada, coincide com o período no qual os trabalhadores já haviam realizado diversas lutas no Paraná. Schmitt (2008) destaca que, as lutas empreendidas pelos trabalhadores iniciaram em 1978 quando um percentual recebeu as primeiras

\footnotetext{
${ }^{5}$ Mais informações sobre a ação dos órgãos governamentais envolvidos com a repressão às organizações de esquerda ver FICO, Carlos. Como eles agiam. Rio de Janeiro: Record, 2001.

${ }^{6} \mathrm{O}$ jornal O Parceleiro circulou em Ariquemes/RO, da década de 1980 à 1998.

7 Instituto Nacional de Colonização e Reforma Agrária
} 
indenizações e tomou consciência de que o valor recebido era injusto. Passaram então, a resistir e reivindicar não apenas maiores valores como também que a estatal os reassentasse no Paraná. Apesar da luta, para muitos, restou apenas a possibilidade de se deslocarem para outros lugares. No entanto, o jornal $\mathrm{O}$ Parceleiro positivou tais deslocamentos. As difíceis condições vividas pelos trabalhadores contrastavam com a informação de que estariam felizes com a indenização, que sequer haviam recebido. A quem coube a intermediação de terras aos trabalhadores desapropriados? Qual o papel da Itaipu Binacional e do Estado nesse processo?

Em meio as lutas, Schmitt (2008) destaca que, o Incra cogitava direcionar os trabalhadores às Glebas que estariam sob seu domínio, à lugares distantes e sem qualquer tipo de infraestrutura. Quanto a isso, o jornal O Parceleiro reconheceu, porém, numa posição ambivalente, buscou positivar a situação ao mesmo tempo que reconhecia a incerteza quanto à qualidade das terras.

Mascarenhas discute que cabia as colonizadoras se responsabilizar pela implantação de infraestrutura nos projetos por elas desenvolvidos, e lucraram significativamente ao mediar o processo de migração (2011). Segundo a mesma autora, em 1979, a CPT (Comissão Pastoral da Terra), juntamente com o Movimento Justiça e Terra $^{8}$, formado pelos desapropriados, discutiam para onde iriam 7.000 famílias desalojadas que ainda não tinham sido realocadas, nem pela Itaipu nem pelo Estado, e que as alternativas oferecidas pelo governo e pela própria Itaipu eram encaminhá-las para o Norte do país. O movimento reivindicava que o Incra realizasse o reassentamento no Paraná a fim de excluir a interferência de imobiliárias e colonizadoras.

Porém, pelos registros produzidos pelo próprio Estado não foi isso que ocorreu. O clima de instabilidade e incertezas quanto ao destino dos trabalhadores favoreceu a atuação de colonizadoras, mas também de imobiliárias particulares. De acordo com Mazzarollo (2003), a pergunta realizada pelo movimento dos desapropriados, em toda a assembleia, era "Para onde ir"? Segundo o mesmo autor, em 1979, o Incra e a Itaipu, atendendo uma reivindicação dos desapropriados, fez circular, entre eles, um aviso, indicando as colonizadoras credenciadas pelo Incra que promoveriam reassentamentos. No entanto, isso não resolveu os problemas dos desapropriados.

8 O Movimento Justiça e Terra foi criado na década de 1980 por trabalhadores dos municípios lindeiros desapropriados pela Construção da Hidrelétrica de Itaipu. Lutavam por indenizações justas de suas terras e pela minimização os impactos socioculturais provocados pela construção da estatal. 


\section{SNI: Mecanismo de informação ou de controle e repressão sobre a questão agrária} no Paraná e na Amazônia?

Em 22 de julho de 1980, o SNI produziu o documento "Problema de terras no Acre - Otássio Pereira de Lima" "9. Nele, descreve que o jornal A Gazeta do Acre, na edição de julho de 1980, noticiou que Otássio Pereira de Lima teria sido ouvido pela Polícia Federal do Estado do Acre, por ter levado colonos paranaenses da região de Itaipu para Rio Branco, em ônibus da Expresso Medianeira, para lhes vender terras do município. Teria sido distribuído um folheto aos colonos, propagando e enaltecendo a qualidade do solo da região e estabelecendo, inclusive, o preço de 8.000 (oito mil cruzeiros) o alqueire que, como afirma o documento, o nominado tinha procuração para vender. É informado que Otássio foi indiciado em inquérito instaurado pela Superintendência da Polícia Federal do Acre, por explorar o nome de uma firma fictícia, denominada de "Colome Melhoramentos Ltda", com sede em Londrina/PR, e por exercício irregular da profissão de corretor imobiliário.

Destas informações supõe-se que, as terras, do mesmo modo, eram irregulares, bem como a procuração de Otássio. Ao buscar maiores informações sobre Otássio e a suposta empresa por ele tocada, encontrei elementos que subsidiam as possíveis relações engendradas nesse processo.

Trata-se de documentos também elaborados pelo SNI. Em seu conjunto, compõe um total de cinco documentos encontrados que, se analisados separadamente, emitem a ideia, num primeiro momento, de que Otássio estaria sendo responsabilizado pela prática ilegal de terras, e em certo momento, contraditoriamente, descrito como alguém com ideais, considerados pelo SNI, como subversivos. Procurei, desse modo, analisar tais registros sob uma perspectiva de processo histórico, sem desvencilhar o caso de Otássio de relações mais amplas e complexas do que ocorria no período no Paraná.

Por processo histórico compreendo, a partir de Thompson, que "[...] o passado humano não é um agregado de histórias separadas, mas uma soma unitária do comportamento humano, cada aspecto do qual se relaciona com outros de determinadas maneiras" (1981, p. 48).

\footnotetext{
${ }^{9}$ Serviço Nacional de Informações. Documento Problemas de Terras do Acre, Otássio Pereira de Lima. Referência BR DFANBSB V8.MIC, GNC.AAA.80010941 - Dossiê 19 páginas.
} 
O documento "Otássio Pereira de Lima"10, de 29 de julho de 1980, traz um histórico da atuação de Otássio no Paraná. Ele é descrito pelo SNI como coordenador da Superintendência do Desenvolvimento da Pesca (Sudepe), político oriundo da extinta Aliança Renovadora Nacional, filiado no MDB (Movimento Democrático Brasileiro) em 1975, vereador de Londrina de 1973 a 1977, deputado em 1974 no Paraná pelo MDB. Desde 1980 possuía má reputação em Londrina devido ser negociador de terras ilegais, sendo arrolado em um caso de venda de imóvel já hipotecado em favor do Banco Bamerindus do Brasil S/A, e que no Fórum da justiça local, o nominado possuía várias ações penais e inquéritos policiais arquivados referentes a questões de terra em que se envolveu irregularmente. Ainda sobre Otássio, o SNI o descreve também como corretor de imóveis e que estaria distribuindo em vários municípios do Estado do Paraná, um folheto intitulado "Terras no Acre", contendo uma conclamação aos desapropriados da Itaipu Binacional nos seguintes termos "Você agricultor, seja indenizado ou não, vá conhecer as terras do Acre".

O título, ao mesmo tempo que é sugestivo, contém um propósito. No período, grande parte das indenizações ainda não haviam sido pagas pela Itaipu. Desse modo, o anúncio era estendido àqueles que também não haviam recebido nenhum valor como forma de tornar atrativa a proposta ao mesmo tempo que poderia isentar a estatal de sua responsabilidade junto aos desapropriados. Questiono, nesse sentido, qual a relação que Otássio teria com a Itaipu. Teria sido uma manobra utilizada pela Itaipu junto à corretores para livrar-se das indenizações? Na sequência, o documento informa:

Grande quantidade de colonos do Sul do País, principalmente do Paraná, tem se deslocado para o Acre e aqui através de Otássio, adquire loteamento de terras irregulares, complicando assim cada vez mais o problema fundiário no Estado. Grande são os lucros do referido elemento com a venda de tais terras ${ }^{11}$.

No documento, Otássio ainda é acusado de emitir cheques sem fundo em favor do Hospital Ortopédico de Londrina/PR, indiciado em vários inquéritos policiais, e que para exercer a intermediação na compra e venda de imóveis rurais, fazia uso da firma "Colome Melhoramentos Ltda", localizada em Londrina, embora a mesma não estivesse cadastrada junto a "Creci" e "Incra", para fins de corretagens de terras e colonização particular. As

\footnotetext{
10 Divisão de Inteligência do Departamento de Polícia Federal. Documento Otássio Pereira de Lima ou Otássio Pereira da Silva. Referência BRDFANBSBZD000033A0099d0001, 11 páginas.

11 Divisão de Inteligência do Departamento de Polícia Federal. Documento Otássio Pereira de Lima ou Otássio Pereira da Silva. Referência BRDFANBSBZD000033A0099d0001, 11 páginas.
} 
Cartas de opção apresentadas por Otássio eram: Terras em Tarauacã/AC, segundo o documento, dadas pelo Senador Altevir Leal, conhecido como grileiro; Carta de condomínio Ituxi, representado por Dilio Ricartes de Oliveira, engenheiro agrimensor, residente e domiciliado em Campo Grande/MS, também com antecedentes por envolvimento em grilagens de terras públicas em Lábrea/AM. Ainda consta que, Otásssio teria vendido terras na região do município de Boca do Acre/ AM, a pessoas oriundas do Sul, tendo causado problemas porque eram devolutas:

Na Amazônia Legal, sempre sem levar em consideração a existência de ocupantes das terras (seringueiros e/ou posseiros), empresas imobiliárias se apresentam como empresas de colonização particular e ao arrepio da Lei, projetam, loteiam e revendem enormes glebas, geralmente públicas e que foram objeto de anterior processo de grilagem, com acentuado aumento após a vigência do novo Imposto Territorial Rural - ITR, instituído pela Lei n ${ }^{\circ} 84.685$ de 06 de maio de $1980^{12}$.

A questão é, a partir dos registros produzidos, o estado sabia o que ocorria, mas se omitia de solucionar. Questões semelhantes envolvendo a venda fraudulenta de terras no Pará foi discutida por Mesquita (2018). O autor também questionou a inércia do Estado frente aos registros produzidos. A meu ver, não há outra alternativa senão entendê-los como uma forma de controle sobre o que acontecia, e que, realmente, a intenção não era solucionar os problemas.

Ao final do documento, solicita-se ao Diretor do Instituto de Identificação do Paraná, informações de Otássio. Dentre os aspectos, dados biográficos, atuais atividades em seu escritório em Londrina, se a migração estaria sendo controlada pelo Governo do estado do Paraná, se o mesmo estaria usufruindo de dinheiro dos colonos para o deslocamento do Paraná ao Acre, se havia contrato escrito, se Otássio tinha autorização escrita dos proprietários e do Incra, atuação política partidária, e atividades que comprovassem sua integridade pessoal administrativa, seus antecedentes políticos e sociais. O documento finda sem as respostas que também não aparecem nos outros documentos analisados. Isso reforça a evidência de que o objetivo não estava em resolver conflitos, apenas obter o controle dos fatos, afinal, com base nessas informações, Otássio como outras situações fraudulentas poderiam ser combatidas.

\footnotetext{
12 Divisão de Inteligência do Departamento de Polícia Federal. Documento Otássio Pereira de Lima ou Otássio Pereira da Silva. Referência BRDFANBSBZD000033A0099d0001, 11 páginas.
} 
Em outro documento, "Venda indiscriminada de terras no Acre" ${ }^{13}$, de 18 de novembro de 1980, registrou-se que de maio a junho o jornal A Gazeta do Acre fez várias publicações sobre vendas fraudulentas de terras no Acre a colonos do Paraná. Assinala como responsável Otássio Pereira Lima, também responsável por distribuir panfletos sobre as terras no Acre em vários municípios do Paraná. O referido panfleto, também publicado pelo jornal A Gazeta do Acre, propagandeava, principalmente, as Glebas São Luiz e Santa Clara, das quais Otássio era procurador e qualificava o solo e a localização. Estava à $100 \mathrm{~km}$ da capital Rio Branco, dispunha de canal de TV, emissora de rádio e faculdades. Segundo o SNI, a reportagem, contraditoriamente, recomendava a compra ressaltando que as terras do Acre produziam tal como as terras do Mato Grosso do Norte e do Sul: "Você agricultor, vá conhecer as terras do Acre, viajando com o Expresso Medianeira, pagando a passagem de ida e volta por C\$8.000,00"14. Destaco como o jornal A Gazeta do Acre estava articulado ao que ocorria no Paraná.

Conforme discute Cruz (2006), as fontes, enquanto linguagens, são produzidas a partir das relações nas quais ela se constitui. Assim, ao mesmo tempo, é instituinte e constituinte de significados no social, devendo ser considerada uma atividade prática e constitutiva desse mesmo social. Com a imprensa, nesse caso, o jornal O Parceleiro e o jornal A Gazeta do Acre, fica perceptível uma construção narrativa na qual interesses articulavam-se em torno ora da denúncia das irregularidades agrárias, ora propagandeando e qualificando as terras do Estado do Acre.

O preço da terra com escritura de compra girava em torno de $\mathrm{C} \$ 3.000,00$ por alqueire com pagamento em um ano ou dois sem juros. Desta feita, o valor da viagem era mais que o dobro de um alqueire. Segundo o SNI, as terras citadas por Otássio, no panfleto, compreendiam uma área de 41.722 ha e firmava entre os pretensos proprietários um contrato de concessão de venda de lotes de imóvel rural. Que embora transcrito em nome de particulares seu domínio era questionado, pois havia uma declaração de nulidade proposta pelo Instituto Nacional de Colonização e Reforma Agrária (Incra) em tramitação no Tribunal de Recursos, envolvendo parte do imóvel em tela.

O documento, porém, não deixa claro porque se questionava apenas parte do imóvel. Esclarece, no entanto, que em decorrência do panfleto, grande quantidade de

\footnotetext{
13 Serviço Nacional de Informações. Documento Venda indiscriminada de terras no Acre Otássio Pereira de Lima. Referência BRDFANBSBV8MICGNCLLL80001064d0001de0001, 11 páginas.

14 Serviço Nacional de Informações. Documento Venda indiscriminada de terras no Acre Otássio Pereira de Lima. Referência BRDFANBSBV8MICGNCLLL80001064d0001de0001, 11 páginas.
} 
colonos se deslocou para o Acre e adquiriram terras de maneira irregular, complicando ainda mais o problema fundiário do Estado. São citados cinco escritórios nos quais Otássio teria feito a negociação de terras, todos eles localizados no Estado do Paraná, nos municípios de São Miguel do Iguaçu, Itacará, Cascavel, Maringá e Céu Azul. As relações se apresentam orquestradas, porém, conforme registrou o SNI, para a o Departamento de Polícia Federal (DPF/AC) não era possível caracterizar tais relações como aliciamento, porque, conforme consta, fora levantado e justificado pelo Incra que a propaganda volante feita por Otássio "destinava-se a convidar os colonos a uma viagem turística em regiões pioneiras, o que é muito normal após a safra"15.

Considerando o perfil dos trabalhadores, é possível cogitar aliciamento. Não se tratava de qualquer trabalhador, a propaganda destinava-se aos atingidos pela Itaipu Binacional, aos trabalhadores que havia ou não recebido a indenização. Por que a Polícia Federal teria desconsiderado esse aspecto? Segundo consta, Otássio foi qualificado e processado por estelionato e pelo exercício ilegal da profissão, mas não informa o que aconteceu com os trabalhadores que já haviam adquirido propriedades.

A hipótese de aliciamento ganha força com o documento SNI "Venda ilegal de terras - Otássio Pereira da Silva", de 26 de fevereiro de 1981. Nele, é informado, novamente, que Otássio distribuía em vários municípios do Paraná um panfleto intitulado "Terras no Acre" contendo informações infundadas. Este anúncio também foi direcionado aos trabalhadores atingidos pela Itaipu, indenizados ou não. Não consegui apurar quantos trabalhadores teriam se deslocado para a Amazônia sem indenização, e sem que a estatal tivesse que pagá-la.

O deslocamento de trabalhadores, por meio de imobiliárias, demonstra como houve a desmobilização de parte do Movimento Justiça e Terra que lutava não apenas por indenizações justas como também pelo reassentamento no Paraná. A desmobilização, conforme ressaltou Mascarenhas, também foi utilizada pela Itaipu, que buscava negociar individualmente com os trabalhadores, como forma de desarticular as possibilidades de mobilização e organização dos atingidos (2011).

Utilizando-se de empresa falsa, sem registro junto ao Incra, a fim de realizar colonização particular, Otássio teria vendido terras devolutas na Boca do Acre/AM à pessoas do Paraná. Nesse documento SNI, de 1981, ainda consta uma reportagem do

\footnotetext{
15 Serviço Nacional de Informações. Documento Venda indiscriminada de terras no Acre Otássio Pereira de Lima. Referência BRDFANBSBV8MICGNCLLL80001064d0001de0001, 11 páginas.
} 
jornal A Gazeta do Acre, sob o título, "Agricultores deixam Itaipu depois de chegar a acordo", noticiada em fevereiro de 1981. Nela, consta que os trabalhadores teriam sido atendidos num acordo com a Itaipu sobre as indenizações. Que após manifestação em frente ao escritório da estatal, em Santa Helena, no Paraná, em uma marcha realizada até Foz do Iguaçu, os trabalhadores tiveram suas reivindicações atendidas com um ajuste de $85 \%$ do valor indenizatório mais a garantia do pagamento em 15 dias após o pagamento da indenização.

Como nesse contexto os trabalhadores já haviam se deslocado por meio das imobiliárias, suponho que grande parte das indenizações não foram pagas pela estatal. A pressão exercida pelos trabalhadores, organizados em movimento, promoveu, ao mesmo tempo, iniciativas particulares de corretores. Muitos viram na propaganda imobiliária uma alternativa mais viável na resolução dos problemas que os afligiam. Ações como a de Otássio serviram para desresponsabilizar a estatal ao mesmo tempo que a isentava da obrigação pelo pagamento de indenizações. No relatório SNI, embora incompleto, consta que:

Diante da realidade exposta - expulsão da terra e precárias opções de reassentamento - torna-se urgente encontrar alternativas que de fato venham a favorecer o povo da terra. Mas para tanto, é preciso permitir que o próprio trabalhador atingido participe na definição e elaboração dessas alternativas. Por exemplo, o documento de reivindicações dos desalojados de Itaipu, "Terras no Paraná e indenização justa", pede reassentamento no próprio Estado do Paraná, através do Incra, ou através de cooperativas de reforma agrária autoadminstrativa, em alguns latifúndios ${ }^{16}$.

No documento, o SNI ressalta a importância de os trabalhadores serem protagonistas no processo de resolução dos conflitos, participando, definindo e criando alternativas. Porém, o mesmo SNI agia de lado oposto a esta possibilidade. Ao fichar, por exemplo, Juvêncio Mazzarollo ${ }^{17}$, como esquerdista, por escrever editoriais contestatórios ao Regime e por disseminar ideias marxistas, menosprezo à autoridade constituída, e claro, por escrever o livro "A Taipa da injustiça. Itaipu x Agricultores expropriados", na década de 1980, livro este anexo ao documento SNI. De acordo com Mascarenhas:

O livro não é apenas denúncia, é também o relato do movimento de resistência dos desapropriados desde a criação, em 1978, do Projeto Arca de Noé que tinha como objetivo discutir as melhores formas de defender os direitos dos

\footnotetext{
16 Serviço Nacional de Informações. Fundo BRDFANBSBZD000048A0014d0003, 9 páginas.

17 Juvêncio Mazzarollo, foi professor e jornalista em Foz do Iguaçu, atuou na Comissão Pastoral da Terra, foi um preso político durante a ditadura pelas críticas políticas ao regime em 1982 e, faleceu em 2014.
} 
expropriados através da formação de grupos de base, as mobilizações dos agricultores, as primeiras assembleias e as vitórias conquistadas, através da pressão de um movimento organizado e pacífico (...)É importante destacar que, tanto O Mausoléu do Faraó quanto A Taipa da Injustiça fizeram parte da organização dos atingidos e da ação da CPT. Essas publicações tinham a intenção de informar, conscientizar e também de organizar os expropriados (MASCARENHAS, 2011, p. 31).

Posteriormente, em 2003, Mazzarollo escreveu "A Taipa da injustiça: esbanjamento econômico, drama social holocausto ecológico em Itaipu”. Questiono por que a Itaipu, causadora de tamanho estrago aos trabalhadores dos municípios lindeiros não fora fichada pelo SNI? Para o historiador Carlos Fico:

Em se tratando de um processo histórico que envolveu grande dose de violência - sobretudo a prisão arbitrária de pessoas, seguida quase sempre de tortura e, várias vezes, de morte -, a ditadura militar brasileira pode ser pensada em conjunto com outros "eventos traumáticos" característicos do século XX, o que situa esse tema no contexto dos debates teóricos sobre a História do Tempo Presente (FICO, 2012, p. 440).

$\mathrm{Na}$ sequência do relatório, as dificuldades dos trabalhadores que estariam se deslocando são destacadas. Imobiliárias como a de Otássio não são citadas:

A situação dos agricultores levados pelas colonizadoras ao Norte do país é, de um modo geral, muito difícil. A maioria das promessas apresentadas para convencer os colonos a se deslocarem para aquelas áreas, não são cumpridas. As principais colonizadoras são: SINOP, CAMPO ALEGRE, INDECO, MUTUMELDORADO, SOMECO, VILA RICA, CODEMAT (Projeto Juína). Estas estão localizadas no Estado de Mato Grosso e são credenciadas pelo INCRA para fazer o reassentamento dos colonos expulsos pela Itaipu Binacional. Outras sio a COLÍDER, COOPERCANA (Terra Nova, Canarana) BRASNORT e Projeto Juruena.... ${ }^{18}$

Não sabemos se os trabalhadores que se deslocaram, intermediados pelas colonizadoras registradas pelo Incra, receberam suas indenizações. No relatório, consta que enfrentaram problemas relacionados ao fornecimento da escritura da terra pelas colonizadoras, quando terminavam de pagá-la. Por esse motivo, ficavam sem o título definitivo por um longo período, ou, nem conseguiam, o que impedia de pleitear empréstimos bancários, causando insegurança e até mesmo a perda do lote. Junta-se a isso, problemas com a qualidade da terra, os altos juros para os que alcançavam financiamento bancário e até mesmo abandono da propriedade. A venda a prazo é indício

18 Fundo BRDFANBSBZD000048A0014d0003, 9 páginas. 
de que os trabalhadores que se deslocaram por meio das colonizadoras também não foram indenizados, assim como os que foram aliciados por imobiliárias não cadastradas pelo Incra. De acordo com Mazzarollo, em 21 de março de 1981, atendendo a inúmeros apelos dos desapropriados, acampados em Foz do Iguaçu, a Itaipu deu o primeiro sinal de interesse no reassentamento:

O INCRA, por solicitação da Itaipu, reservou 200 lotes no Estado do Acre para os expropriados, que serão vendidos em condições excepcionais: área de 100 hectares, com infra-estrutura, perto da Capital do Estado. Preço:4.000 cruzeiros por hectare, com prazo de carência de 6 a 12 anos para pagar, sem correção monetária. Existem, no momento, 50 famílias interessadas neste programa, e elas deverão começar a se deslocar para o Acre na segunda quinzena de abril. Como as áreas do Acre são muito procuradas, a expectativa é de que, em busca de área bem maior do que aquela que possuíam no reservatório, 200 famílias deverão, por livre e exclusiva escolha, se reassentar naquele Estado (MAZZAROLLO, 2003, p. 137).

Não havia alternativas para os trabalhadores desapropriados que não conseguiram serem reassentados no Estado do Paraná, mas para a Itaipu a ida para o Acre era por livre e exclusiva escolha. A intermediação de terras pelo INCRA, junto a Itaipu, responde a tese que levantei, sobre o fato de a Itaipu não ter se responsabilizado pelo pagamento de indenização para muita gente. Ainda mais grave, é a própria inoperância do Estado junto aos trabalhadores. As terras, mesmo intermediadas pelo Incra, responsável pela sistematização de diversos projetos de colonização na Amazônia no período, eram vendidas.

Segundo Mazzarollo, em setembro de 1981, o assessor de relações públicas da Itaipu, Rubens Nogueira, anunciava em nota oficial que:

Até o final de 1982, mais de 700 famílias de posseiros e arrendatários já terão se transformado em proprietários de terras nos Estados do Acre, Bahia e Paraná (município de Arapoti), graças às providências tomadas pelo INCRA em colaboração com a Itaipu. Cada desapropriado tem o direito de escolher o local onde gostaria de viver. Sempre pensando no homem, a Itaipu Binacional, além de pagar as indenizações, providencia para que as famílias desapropriadas que desejam participar de reassentamentos dirigidos pelo INCRA possam fazê-lo da melhor forma. Para tanto, oferece ônibus e caminhões para o transporte. Ainda não se ouviu falar de nenhum problema de adaptação de nenhuma família reassentada por Itaipu (MAZZAROLLO, 2003, p. 139).

Para a Itaipu, os problemas dos desapropriados estariam resolvidos até o final de 1982, e a partir de suas escolhas, homogeneizando e positivando um processo complexo e extremamente conflituoso como demonstrado pelos registros produzidos pelo próprio 
governo. Os problemas de adaptação, que segundo a Itaipu inexistiram, podem ser identificados em depoimentos presentes em uma carta entregue pelos trabalhadores do Acre, ao Secretário de Agricultura Claus Germer, na ocasião em que ele esteve presente no Estado, para que o mesmo entregasse ao então governador do Paraná, José Richa:

Nossas raízes, nossa cultura e nosso coração ainda permanecem aí. Hoje temos um pedaço de terra, mas somente a terra não basta. Chegamos a esta dura realidade. A terra, única coisa que o Estado do Acre pôde nos oferecer, é boa, mas as dificuldades são enormes. Faltam escolas, estradas, assistência médica. O calor é forte demais, chove demais de novembro a maio, enquanto na época da estiagem os córregos secam, obrigando-nos a cavar poços ou transportar água de lugares distantes. Falta água em todos os lotes. O Paraná é um Estado rico, governado por uma equipe dinâmica, por isso pedimos ao governo que nos ajude a continuar a batalha aqui. Para isso pedimos que nos ajude a construir um hospital e adquirir tratores para construir açudes, consertar estradas e destocar roças (MAZZAROLLO, 2003, p.141 e 142).

A carta é significativa. Apesar da relação de pertencimento com o Paraná, a terra adquirida no Acre era condição de sobrevivência. Por este motivo, apesar de todas as intempéries sofridas, semelhantes àquelas que identifiquei com relação aos trabalhadores que migraram nas décadas de 1970 e 1980 para Rondônia (PAULA, 2019), os trabalhadores solicitavam auxílios ao governador do Paraná, como forma de permanecerem no Acre, haja visto que, dada a falta de condição, voltar era algo impossível. Os dramas vividos pelos trabalhadores no Acre também foram reconhecidos pelo deputado paranaense Santinho Furtado, em um pronunciamento sobre a realidade da colonização na Câmara Federal:

É o próprio Estado que fustiga o cidadão, desaloja a família de sua terra natal, empurra legiões inteiras de um lado para outro em busca de esperanças perdidas, premiando-as com dolorosas frustrações, como está acontecendo com milhares de paranaenses. Não bastasse o longo e penoso período das desapropriações (muitas ainda pendentes até hoje), que provocaram inclusive repetidas manifestações de protesto contra a Itaipu Binacional, os lavradores são agora submetidos a esse novo holocausto na região amazônica, enganados pelo próprio governo, que descaradamente mentiu aos agricultores (MAZZAROLLO, 2003, p.142).

O deputado, certamente, não se referia apenas aos trabalhadores que reivindicavam recursos do governo do Paraná como condição de permanência no Acre, mas também, aos que, impossibilitados de conquistarem uma propriedade, devido os casos já citados, de venda fraudulenta de terra, acabaram tangidos não apenas pela Itaipu, mas pelas colonizadoras, empresas particulares e pelo próprio Estado. 
Nesse processo, a terminologia holocausto, utilizada por Mazarollo, com relação aos danos ecológicos em Itaipu, e pelo Deputado, com relação à Amazônia, são significativas. $\mathrm{O}$ deslocamento dos trabalhadores para a Amazônia não ocorreu sem o enfrentamento de inúmeros problemas e conflitos, como falta de água, estradas, regularização fundiária, acesso à terra, falta de educação, saúde, financiamento bancário, assim como presenciaram, novamente, a destruição ambiental no Norte do país provocada pelos contínuos e intensos desmatamentos.

A partir desse cenário de incertezas, estendidas do Paraná ao Norte do país, destaco o papel do Estado na proteção e defesa da estatal. A situação de instabilidade gerada pela Itaipu e pelo Estado transformou a possibilidade de intermediação de terras em um grande negócio fraudulento. Isso isentou a estatal de realizar a intermediação de terras no Paraná e o pagamento de indenizações, já que colonizadoras particulares, e imobiliárias, fizeram, a seu modo, esse papel. Tal processo, em grande medida, também isentou o Estado de responsabilidade com esses trabalhadores junto aos projetos de colonização oficial sistematizados pelo Incra no período, já que os trabalhadores não realocados no Paraná tiveram que pagar por seus lotes no Estado do Acre.

\section{O caso Otássio e a questão agrária no Paraná e na Amazônia}

O que o caso Otássio nos diz sobre a questão agrária no Paraná e na Amazônia? Como os mecanismos de repressão atuaram durante o regime militar nessas localidades?

Primeiro, ressalto que, os registros aqui problematizados, revelaram uma face do processo de expansão das relações capitalistas para a região Norte do país que se difere do estudo que realizei acerca dos migrantes que se deslocaram, em sua maioria, da região Sul do país em busca de terra nos projetos de "colonização" do Incra. O conjunto dos trabalhadores migrantes pesquisados vivenciaram experiências distintas que vão desde a marcação das propriedades à processos conflituosos com fazendeiros, indígenas, à privação a recursos básicos como saúde e educação até a falta de subsídios, escoamento da produção e a perda da propriedade da terra (PAULA, 2019).

O estudo indicou que se tratava de trabalhadores informais, temporários, que se deslocavam com poucos recursos, e à medida que chegavam, desenvolviam diversas formas de trabalho enquanto lutavam para conseguirem suas propriedades. Capinando terrenos, carpinteiros, derrubando mata ou arrendatários, são ocupações que mais apareceram na pesquisa (PAULA, 2019). 
Assim, o que os diferencia dos trabalhadores atingidos pela Itaipu é a intermediação realizada tanto por colonizadoras quanto por imobiliárias particulares, como a que evidenciei no decorrer desse trabalho. Porém, o que em comum tem esses trabalhadores é a constante mobilidade que decorre, em grande medida, pelas mudanças e transformações nas relações sociais capitalistas que os empurram, não sem luta, a buscarem pelas possibilidades que se apresentam. É preciso compreender que as vezes não há alternativas. O trabalho é expressão de nossa existência e uma vez que as condições de manutenção da existência são retiradas, nesse caso a terra, resta aquilo que homens e mulheres dispõem, a força de trabalho. No horizonte dos trabalhadores, tanto colonizadoras, quanto imobiliárias solucionariam o problema da perda da terra.

Nesse ínterim, o caso de Otássio, demonstra, como foi, para os trabalhadores, vivenciar um processo de perda, de expectativas, e novamente, de frustração em torno da propriedade da terra. Considerando que, os registros do SNI foram produzidos no calor do momento, consegui compreender a natureza do problema agrário brasileiro e que o regime militar não tinha como intenção solucionar os conflitos. Todos os documentos produzidos pelo SNI analisados são de caráter confidencial, produzidos para informar o governo sobre o que ocorria, ao mesmo tempo que possibilitava manter o controle sobre o que era desejável ao regime militar.

Considero, assim, que, os registros produzidos serviram como mecanismo de controle e repressão durante o regime militar. A relação do Estado nesse processo foi de proteção e defesa da estatal, enquanto, também não tomava iniciativas para solucionar os problemas que os trabalhadores enfrentavam, no Paraná e na Amazônia. A situação de instabilidade gerada pela Itaipu e pelo Estado transformou a possibilidade de intermediação de terras em um grande negócio fraudulento. Isso isentou a estatal de realizar a intermediação de terras no Paraná e o pagamento de indenizações, já que colonizadoras particulares, e imobiliárias, fizeram, a seu modo, esse papel.

Tal processo, em grande medida, também isentou o Estado de responsabilidade com esses trabalhadores junto aos projetos de colonização oficial sistematizados pelo Incra no período. A partir da década de 1970 o Incra desenvolveu uma série de projetos de Colonização no Estado de Rondônia, os PICs (Projetos Integrados de Colonização), os PADs (Projetos de Assentamento Dirigido) e os PARs (Projetos de Assentamento Rápido). No entanto, não identifiquei nos registros do SNI ou da Comissão Pastoral da Terra evidências sobre a destinação dos trabalhadores desapropriados pela Itaipu em 
algum desses projetos. A única evidência faz referência a um projeto desenvolvido no Acre pelo Incra e por solicitação da Itaipu, como assinalei.

De acordo com Prieto (2021), durante a ditadura civil militar, uma das estratégias de apropriação criminosa de terras públicas foi a tentativa de regularizar as terras por meio de "laranjas", via falsas procurações. O artigo 164 da Constituição de 1967 (BRASIL, 1967, p. 38), previa a legitimação da posse de até cem hectares de terras públicas por aqueles que a tronassem produtivas. E, no caso de execução de planos de reforma agrária havia a aprovação prévia do Senado Federal para alienação e concessão de terras públicas com área superior a três mil hectares.

Prieto (2021), porém, ressalta que, era possível adquirir terras públicas federais ou estaduais com áreas maiores do que os 100 hectares, permitida à época pela ditadura, fato que, inclusive, foi substanciado na Constituição Federal de 1988, evidenciando, assim, "que o Estado sabia das práticas grileiras operadas no Estado de exceção rotineirizado" (PRIETO, 2021, p. 156). A Constituição, portanto, prevê revisão de terras públicas doadas, vendidas ou concedidas, com áreas superiores à três mil hectares, realizadas de $1^{\circ}$ de janeiro de 1962 à 31 de dezembro de 1967, porém, o Congresso até hoje nada fez para promover essa revisão (PRIETO, 2021).

Assim, é possível que Otássio tenha atuado como "laranja" na intermediação de terras que envolveu o Incra, a Itaipu e os trabalhadores desapropriados. Esse processo evidencia que a exploração se dá dentro dos marcos do Estado, seja isentando-se das responsabilidades, seja reprimindo a classe trabalhadora, como ficou evidenciado nos registros produzidos pelo SNI. Essa substancialidade do Estado é o que confere a hegemonia às classes dirigentes para continuarem atuando enquanto tal, como refletiu Gramsci: “A unidade histórica das classes dirigentes se produz no Estado e sua história é, essencialmente, a história dos Estados e dos grupos de Estado" (GRAMSCI, 2009, p. 129).

Ainda sobre hegemonia das classes dirigentes, Raymond Williams (2011) propõe não apenas a constatação, mas a reflexão sobre as condições e o modo como os processos hegemônicos se constituem. Os registros produzidos pelo SNI, permitiram, assim, perceber, exatamente, como se dá a construção hegemônica e como o Estado teve um papel primordial.

Na Amazônia, os conflitos agrários se intensificaram nos anos que se seguiram. No Paraná, o processo de mecanização transformou vários trabalhadores em 
arrendatários, meeiros e trabalhadores volantes (MOREIRA, 2016). A alteração da base técnica devido às mudanças sociais de produção no campo, levou muitos trabalhadores a perderem suas terras e migrarem para a Amazônia.

Esse processo demonstra as pressões vividas pela classe trabalhadora, de Norte à Sul do país, frente à projetos tidos como sinônimo de "modernização" e "desenvolvimento". A luta pela sobrevivência empreendida pelos trabalhadores desde que foram desalojados, contrasta com a imagem de opulência construída em torno da Itaipu. Através de diversos projetos na área ambiental e social a estatal busca construir uma memória que tenta silenciar outras versões, evitando assim, que aflorem problemas relativos à expropriação, como o que tratei nesse artigo. Como um processo histórico, dinâmico e em movimento, a história, como adverte Fontana, não é e não deve ser um "modelo único da evolução humana com suas concepções mecanicistas de progresso, que aparece como produto das "leis da história", com escassa participação dos homens" (2004, p. 473). Nessa direção, o direito à memória e a História (PAOLI, 1992) são possíveis quando nos deparamos com registros dissonantes as versões oficiais, ou, nesse caso, os produzidos oficialmente pelo Estado, que além de registrar os problemas assinala sua omissão.

Não são os trabalhadores ou a Comissão Pastoral da terra (o que não deslegitimaria, em hipótese alguma, a escrita da história) reconhecendo os problemas vividos pelos trabalhadores, mas o próprio Estado. Sem dúvida, o peso dos registros, por tratar-se de uma fonte oficial, confidencial, ganha relevância frente ao contexto vivido, marcado, dentre outros elementos, pelo negacionismo histórico, principalmente com relação as atrocidades cometidas pelo regime militar. Em muitas versões, a Itaipu não aparece como culpada pela tragédia humana, social e ambiental provocada. No presente, a estatal segue sob o slogan de "energia limpa". Para muita gente, essa energia foi e é produzida à custa de muito sofrimento.

\section{Considerações finais}

A relação entre os desapropriados pela Itaipu, o Estado e a ditadura no Paraná e na Amazônia, de modo específico, no Acre e em Rondônia, é uma das faces de um processo complexo que envolve outros agentes, e que precisa continuar sendo investigado. Assinalo, principalmente, para a possibilidade de evidenciar outras relações cuja base de sustentação está firmada na conivência do Estado junto a grilagem. Como 
destaca Prieto (2021), a Amazônia, passou por um conjunto de apropriações privadas de terras devolutas no projeto estratégico e geopolítico de ocupação da Amazônia levada a frente pela ditadura militar que vinculou a reforma agrária aos projetos de colonização.

Não basta, porém, contrapor essa visão denominando-a como uma contrarreforma agrária (IANNI, 1979), mas compreender quais relações e agentes estiveram presentes nesse processo, no qual, o Estado autoritário, empenhou esforços na criação de diversos órgãos oficiais ${ }^{19}$. O que ocorria na Amazônia é parte do processo histórico de transformação das relações capitalistas e da dinâmica do que ocorria de modo mais amplo no contexto nacional. Evidenciar possíveis narrativas e revelar os agentes que atuaram nesse processo é um caminho a ser percorrido. Como adverte. Fico, "devemos continuar lutando pelo direito de fazer e conhecer a história brasileira em sua plenitude (2008, p.77).

\section{Referências}

CRUZ, H. et al. Outras Histórias: Memórias e Linguagens. São Paulo: Olho D‘água, 2006.

FICO, Carlos. A Ditadura Documentada. Acervos desclassificados do regime militar brasileiro. Acervo, Rio de Janeiro, v. 21, no 2, p. 67-78, jul/dez 2008.

Como eles agiam. Rio de Janeiro: Record, 2001.

. História do Tempo Presente, eventos traumáticos e documentos sensíveis. O caso brasileiro. Varia História, Belo Horizonte, vol. 28, n 47, p.43-59, jan/jun 2012, p. 44.

FONTANA, J. A História dos Homens. Tradução Heloisa Jochims Reichel e Marcelo Fernando da Costa; revisão técnica Daniel Reis Filho. Bauru, SP: Edusc, 2004.

MANARIN, Ordilei. Peões da barragem. Memórias e relações de trabalho dos operários da construção da Hidrelétrica de Itaipu - 1975-1991. Marechal Cândido Rondon, 2008.

MASCARENHAS, Milena Costa. Poeira x Unicon: confrontos e contrapontos entre expropriados e Itaipu - Marechal Cândido Rondon, 2011.

MAZZAROLLO, Juvêncio. A taipa da injustiça: esbanjamento econômico, drama social e holocausto ecológico em Itaipu. 2. ed. São Paulo: Loyola, 2003.

\footnotetext{
${ }^{19}$ Nesse período, foi criado o Incra pelo Decreto-Lei n. 1.110 de 9 de julho de 1970, que extinguiu o IBRA e o INDA e transferiu para o novo órgão todas as atribuições dos antigos institutos. No mesmo período, foram criados o Programa de Integração Nacional (PIN) e o Programa de Redistribuição de Terras (PROTERRA) (PIETRO, 2021).
} 
MAZZAROLLO, Juvêncio. A taipa da injustiça: Itaipu x Agricultores expropriados. Comissão Pastoral da Terra. Secretariado Regional do Paraná, Curitiba, 1980.

MESQUITA, Thiago Broni de. "Uma estrada revela o mundo": O SNI e os conflitos pela posse da terra no Pará. Universidade Federal do Rio de Janeiro, Rio de Janeiro, 2018.

MOREIRA, V. J. A Produção Agropecuária: Trabalho e Resistência. Revista Perspectiva Geográfica, v. 7, n. 8, 2012. Disponível em: http://e-revista.unioeste.br/index. php/pgeografica/article/view/9347/6962. Acesso em: 15 jul. 2016.

PAOLI, Maria Célia. Memória, história e cidadania: o direito ao passado. In. O direito à memória: patrimônio histórico e cidadania. São Paulo: DPH, 1992.

Paula, Cátia Franciele Sanfelice de. Trabalhadores e a transformação das relações capitalistas em Rolim de Moura 2019 -RO (1970-2018) / Cátia Franciele Sanfelice de Paula. - 1. ed. - Curitiba: Appris, 2019.

. Mudanças no mundo dos trabalhadores: os pescadores profissionais de Guaíral PR (1970-2011) / Cátia Franciele Sanfelice. - Marechal Cândido Rondon, 2012.

SCHMITT, Judite Veranisa. Os atingidos por Itaipu: história e memória. Oeste do Paraná, décadas de 1970 a 2000 / Judite Veranisa Schmitt. - Marechal Cândido Rondon, 2008.

THOMPSON, E. P. A miséria da teoria. Ou um planetário de erros. São Paulo: Copyleft, 1981.

WILLIAMS, R. Cultura e Materialismo. Trad. André Glaser. São Paulo: Unesp, 2011.

\section{Fontes}

Jornal O Parceleiro, de 04 de julho de 1981

Jornal A Gazeta do Acre, edição de julho de 1980.

Serviço Nacional de Informações. Documento Problemas de Terras do Acre, Otássio Pereira de Lima. Referência: BR DFANBSB V8.MIC, GNC.AAA.80010941 - Dossiê 19 páginas.

Divisão de Inteligência do Departamento de Polícia Federal. Documento Otássio Pereira de Lima ou Otássio Pereira da Silva. Referência BRDFANBSBZD000033A0099d0001, 11 páginas.

Serviço Nacional de Informações. Documento Venda indiscriminada de terras no Acre Otássio Pereira de Lima. Referência: BRDFANBSBV8MICGNCLLL80001064d0001de0001, 11 páginas.

Serviço Nacional de Informações. Documento Venda ilegal de terras - Otássio Pereira da Silva. Referência: BR DFANBSB V8.MIC, GNC.LLL.81001405, 9 páginas. Serviço Nacional de Informações. Fundo BRDFANBSBZD000048A0014d0003, 9 páginas.

Artigo recebido em 25 de janeiro de 2021. Aprovado em 30 de abril de 2021. 